
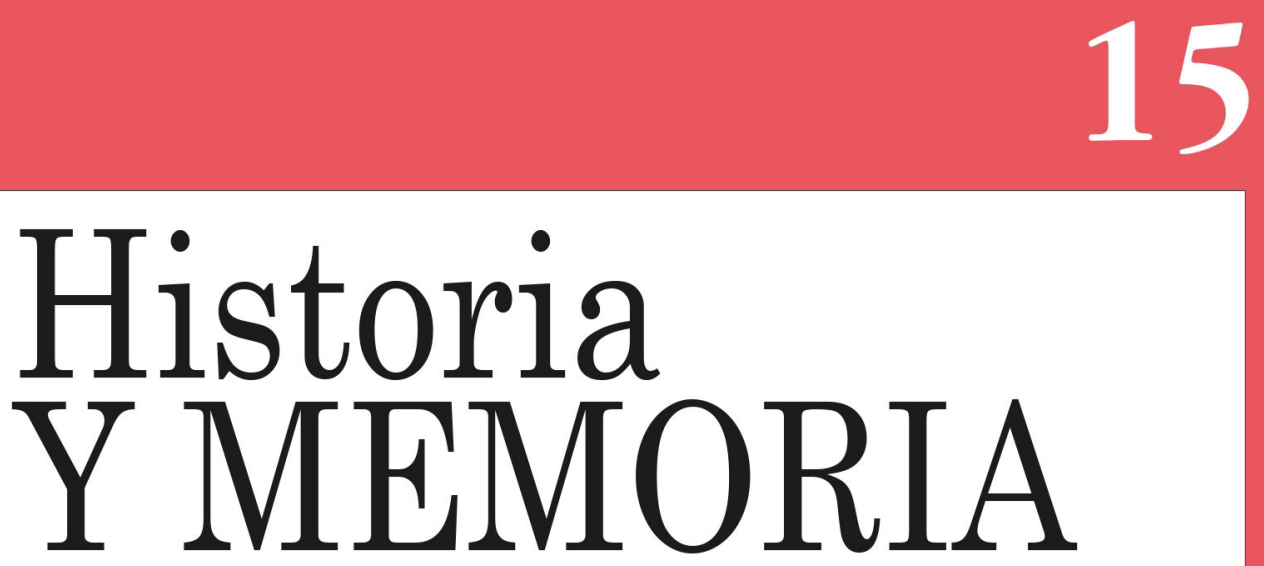

ISSN: 2027-5137 Julio - Diciembre, Año 2017 - Tunja, Colombia

Castro Gutiérrez, Felipe. Historia social de la Real Casa de Moneda de México. México: UNAM, Instituto de Investigaciones Históricas, 2012.

https://doi.org/10.19053/20275137.n15.2017.6224

Julián Andrei Velasco Pedraza

orcid.org/0000-0001-5563-1895

Páginas: 351-357

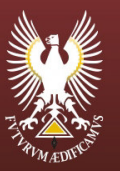




\title{
Castro Gutiérrez, Felipe. Historia social de la Real Casa de Moneda de México. México: UNAM, Instituto de Investigaciones Históricas, 2012.
}

\author{
Julián Andrei Velasco Pedraza ${ }^{1}$ \\ El Colegio de Michoacán A.C. - México
}

Toda institución, sea cual sea su tarea, posee un personal que la hace operar. Verdad de perogrullo que comúnmente se olvida, pues obviamente existe un componente humano que dirige una entidad, pero también uno que realiza diversas tareas materiales que hacen posible su accionar. Esto es lo que ha solido ocurrir en los estudios de las instituciones de la monarquía hispánica, pues mayoritariamente se han interesado por los cargos de mayor importancia política o prestigio social; y se ignoran personajes de poco rango, pero que ejecutaban, día a día, el trabajo pesado, el papeleo necesario o las actividades más engorrosas. En otras palabras, se ha postergado la tarea de una verdadera historia social de las instituciones con el fin de mostrar la gran complejidad de los aspectos humanos, en los engranajes institucionales a través del tiempo.

El libro de Felipe Castro, experto en historia social novohispana, se enfoca y desarrolla esas dimensiones sociales para la Real Casa de Moneda de México. Esta, habiendo sido la entidad encargada de acuñar las monedas del rey requirió, desde su establecimiento en 1535, una amplia serie de labores

1 Candidato a Doctor en Historia (El Colegio de Michoacán - México), Magíster en Historia (El Colegio de Michoacán, 2017), Magíster en Historia (Universidad Autónoma de México, 2015). Publicaciones recientes: «Retornar al derecho: notas para una historia cultural de lo jurídico». Revista Prohistoria XIX, nº 27 (2016): 3-26. «Enlistar un gobierno provincial: una relación de empleo de la provincia de Tunja (Nuevo Reino de Granada, 1787)». Relaciones. Estudios de Historia y Sociedad 147, (2016): 199-250. $ه$ javelasco88@gmail.com (D) http://orcid.org/0000-0001-5563-1895 
de fuerza y destreza, en las cuales empleaba a trabajadores de variado origen social y económico. La vida de quienes desempeñaban tales actividades es el objetivo principal de la obra. Desde un enfoque que el mismo autor califica como microsocial (para él preferible a microhistórico), nos lleva por las condiciones laborales, sociales y económicas de los forjadores monetarios, aunque igualmente por las principales características y los procesos más significativos de la ceca mexicana hasta 1821.

A través de cinco capítulos, Castro analiza los principales momentos y aspectos de la institución. El origen $y$ el funcionamiento en sus primeros años (Cap. 1) otorgan el punto de partida para hablarnos del tipo y funciones de los oficios y su dinámica institucional (Cap. 2). El esquema de cargos de la Casa de Moneda fue objeto de cambios con la Nueva Planta, tanto en su funcionamiento como en sus dimensiones materiales hacia finales de la tercera década del siglo XVIII (Cap. 3). Los elementos anteriores si bien constituyen, en ocasiones, aspectos meramente institucionales o técnicos, son necesarios para entender el mundo laboral y social de los empleados y trabajadores cuyas condiciones, en uno y otro, era modestas, precarias y hasta miserables (Cap. 4). Ante ello, no pocas veces se vieron en la necesidad de extraer furtivamente algunos pesos o residuos argentíferos, lo cual fue perseguido, juzgado y castigado por un tribunal privativo para sus miembros (Cap. 5).

Para su análisis, el autor recurrió a diversa documentación, entre la que destaca una amplísima cantidad de expedientes judiciales que generaron la institución y sus miembros. De allí entresacó miles de indicios con el fin de «reconstruir y analizar el origen, situación social y familiar, relaciones laborales, ideas y actitudes de los trabajadores [...]» (p.13). De esta manera, la obra se desvía del enfoque institucional (de corte tradicional) y económico con que ha sido analizada la institución o su producción monetaria. Además, se combinan de forma equilibrada la descripción del régimen jurídico de los cargos, las funciones establecidas, el ejercicio de 
ellos y la vida cotidiana de los trabajadores manuales dentro y fuera de la Casa de Moneda.

La afirmación anterior no aplica del todo para los encargados de coordinar las tareas y procesos («oficiales mayores»), ya que el autor se interesa por el conjunto de trabajadores manuales de la institución. Los oficios que se ocupaban de la producción de moneda como tal, se distinguían entre «monederos» o acuñadores y los operarios u obreros brazajeros, estos últimos, encargados de la hornaza o fundición. Esta era realizada por distintos capataces que debían procurarse los suficientes trabajadores libres. Por su actividad específica, la ceca requirió de personas que fundieran, golpearan, cortaran, movieran, prensaran y acuñaran los metales. El aumento de la demanda de moneda llevó a que la institución pasara de tener 110 operarios en 1729, a más de 300 en 1787 y casi 400 en 1803 (p. 138). Semejante cantidad de empleados era el reflejo de una complejidad técnica y material que se dividía en distintas secciones, cada una con sus especialidades técnicas (o artesanales) como carpintería, herrería, fundición y operación de molinos, entre otras. Sin embargo, hasta las reformas de la Nueva Planta, la Casa de Moneda se asemejaba más a un obraje.

Esta situación cambió en el siglo XVIII, aunque muy lentamente. A pesar que se promovieron diversos avances materiales, tecnológicos o de gestión, estos se implementaron con los años. Entre ellos, resaltan la ampliación de la infraestructura, un nuevo método de fundición que requirió el ajuste de la maquinaria y hasta mejores maneras de recuperar el metal que sobraba en cada una de las operaciones de fabricación. Tanto las máquinas como las ideas para los cambios tecnológicos, no fueron simples importaciones de Europa, como suele pensarse. En realidad, se presentó una adaptación de ellas en medio de un «localismo tecnológico» (p. 112) que también propuso innovaciones técnicas y de operación aunque la Corona lo viera con cierta sospecha.

Los cambios tecnológicos en la Casa de Moneda eran solo una parte de los principales cambios institucionales a 
comienzos del siglo XVIII. Las leyes de Nueva Planta (1716) llevaron a que en 1718 se eliminaran las concesiones de acuñación a particulares en las cecas peninsulares. La medida tuvo éxito como para que diez años después se extendiera a Las Indias, aunque sus ordenanzas solo se aprobaron en 1730 (p. 75). En 1750, las particularidades novohispanas dieron lugar a un reglamento específico para su ceca, la que serviría de modelo a otras casas. Las reformas estaban dirigidas a una administración "directa» por parte del rey, pues además de cancelar las concesiones particulares, las cecas comprarían el metal a los introductores, se rebajó la cantidad de plata que debía llevar la moneda y se establecieron nuevos oficios o se ajustaron sus funciones. Por supuesto, algunas modificaciones debieron aguardar más tiempo que otras y, desde el comienzo de las transformaciones, los oficiales menores y operarios se resistieron al nuevo sistema, aunque no fueron los únicos.

Otro de los grandes procesos que afectó a la ceca fue la patrimonialización de los principales oficios en los siglos XVI y XVII, lo cual dio lugar a cierta "pérdida" de autoridad de la Corona sobre la entidad. Como bien apunta el autor, este fenómeno debe verse en la forma de gobernar en la época. No obstante, la venalidad en los oficios favoreció que varios personajes los adquirieran como fuente de ingresos económicos y los arrendaran a terceros, y a ello se le sumaban los convenientes vínculos que algunos tuvieron con mercaderes de plata, algunos de los cuales aspiraron a controlar ciertas operaciones de la institución. Si bien había intereses económicos para adquirir los oficios de la Casa de Moneda, «Existían también motivaciones de índole patrimonial, pero vinculadas con preocupaciones sobrenaturales» (p. 66). Con las reformas, la Corona tomó las riendas de la ceca por medio de cargos como el superintendente y el contador, y su salario, el de los demás oficiales mayores, de los oficiales menores, así como el de los trabajadores, dependió, en distinto porcentaje y según la tarea, de las cantidades acuñadas.

La parte más interesante del libro es la dedicada a los trabajadores y avatares de su existencia. Ellos empezaban por diferenciarse económica, social e institucionalmente de 
los empleados, sus jefes. Sin embargo, las relaciones laborales no se reducían al cumplimiento de reglamentos, a los simples mandatos de unos y la obediencia o resistencia de otros. En realidad intervenían "vínculos personales que pasaban, según el caso, por la lejanía autoritaria, la indiferencia administrativa, el clientelismo e incluso la amistad» (p. 134), aunque los empleados siempre trataron de mantener una buena imagen ante sus subalternos y de cuidar la disciplina entre ellos. Los trabajadores que ingresaban o cambiaban de puesto en la Casa de Moneda, requirieron de calificación previa, o de al menos cierta habilidad manual; mientras que más de la mitad de ellos fueron españoles (63.2\%), cierto porcentaje indios (18.1\%), un poco menos mestizos (12.9\%), y muy pocos negros o mulatos (5.8\%). Pese a que había razones para la discriminación, parece que las diferencias de «calidades» no suscitaron mayores altercados o rechazos, ya que "[...] unos y otros trabajaban juntos, vivían en lugares similares, se divertían en las mismas cantinas y compartían ideas y prejuicios» (p. 140). Ante las autoridades de la ceca, cada una de las calidades sí mereció ciertos matices en su trato a la hora de un juicio.

Una diferencia adicional existía por ser trabajadores propietarios o suplentes, que no solo era remarcada por los directivos, sino en el mismo trato cotidiano de los operarios y en su retribución. Esta, podía variar por la naturaleza de la labor, si era por jornal, por día de trabajo o por tarea desempeñada. En general, lo ganado por los operarios les alcanzaba para vivir, pues devengaban más que un peón de hacienda y más o menos lo mismo que un artesano agremiado. No obstante, ciertas obligaciones económicas o una familia numerosa podían hacer que el dinero no fuera suficiente, incluso, para no vivir en la miseria. En la vida laboral como social de estos individuos también intervenían su estado civil, los amigos, el compadrazgo y el crédito personal. Cada uno de estos aspectos es documentado por el autor para evidenciar las distintas facetas de la vida de los trabajadores de la Casa de Moneda. En cuanto a su relación con la institución, se puede hablar de cierto "orgullo de oficio» y cierta conciencia gremial. Una de sus manifestaciones fue en las condiciones de salud, 
enfermedad y ayuda mutua que terminaron por constituir un establecimiento de socorro para los miembros de la institución para asistir a enfermos y jubilados (pp. 170 y ss.).

La delincuencia de los trabajadores, se reflejaba como «una imagen en negativo de la institución», debido a su situación económica y social (p. 181). El juzgamiento de los robos en la Casa de Moneda no solo deja ver las acciones de los operarios, sino las maneras en que las autoridades intentaban mantener el orden y las jerarquías, así como las ideas sobre el cumplimiento de los deberes. Las medidas de control para evitar los hurtos, como fueron revisiones diarias a cada trabajador, eran burladas por distintas triquiñuelas que podían involucrar la colaboración de varios individuos y los más elaborados o curiosos escondites para el metal o las monedas. Una vez cometido el delito y bajo sospecha o acusación, se procedía a juzgar por medio de un tribunal privativo inscrito en una lógica corporativa. El superintendente, con asesor letrado, procedía a castigar los crímenes cometidos en la Casa de Moneda, pidiendo la opinión del fiscal del crimen de la audiencia. Igualmente, juzgaba los asuntos civiles y la falsificación de moneda, quedando las apelaciones para virrey.

La justicia de la Casa de Moneda rozaba con otras. Era problemático cuando uno de los acusados tenía fuero militar o cuando se refugiaba en una iglesia para no ser apresado. En cambio, había mutua colaboración con el Tribunal de la Acordada. Los motivos para cometer los robos eran muy variados, aunque muchas veces alegaban urgencias personales como "la enfermedad de un hijo, el parto de una esposa, la necesidad de adquirir lo indispensables para su familia, o de pagar el alquiler de su vivienda para no ser echados a la calle» (p. 193). Estas condiciones eran utilizadas por los defensores para conseguir rebajas en las penas o también recurrían a justificaciones de orden sobrenatural, como la influencia del diablo. En cuanto a los castigos, no eran mecánicamente aplicados, sino objeto de discusión jurídica y adecuaciones. Los más comunes, entre otros, fueron la expulsión de la institución, el servicio personal, el destierro y el envío a presidio. Cada uno de ellos tenían su significado y consecuencias sociales 
propias: el presidio era muy temido, el servicio personal en obras pública era muy conveniente para las autoridades y de la pena de muerte no hubo un solo ejemplo en los tres siglos de la Real Casa de Moneda.

La obra de Felipe Castro goza de una amena escritura que contribuye a hacer más vivido el retrato vital de los trabajadores de la institución. Entremezcla historia institucional, de la tecnología y de los hombres. Igualmente, relaciona la entidad con su contexto urbano, político y económico, ya que la Casa de Moneda o la vida de sus trabajadores siempre se vio afectada por distintos sucesos o coyunturas externas a la institución, por ejemplo, durante la Independencia cuando su productividad descendió mucho, se crearon otras cecas y finalmente pasó a ser una ceca imperial y luego nacional.

Podría decirse que la obra está más orientada al siglo XVIII a pesar de que abarca los tres siglos de dominio hispánico. Esto hace que, por ejemplo, la imagen que resulta de la institución en el siglo XVII quede algo borrosa. Obviamente se pueden observar las dificultades heurísticas y de complejidad temática para construir una obra como esta desde el siglo XVI, pero queda esa veta de investigación. Finalmente, este libro puede verse como un ejemplo de lo que se puede elaborar para las demás cecas indianas, cuyos archivos históricos custodian valiosas series documentales a la espera de investigadores. 